\title{
O CONTROLE FINALÍSTICO DE INCENTIVOS TRIBUTÁRIOS À LUZ DO PROPÓSITO DO DIREITO NA TEORIA DE SCOTT SHAPIRO: UMA ANÁLISE CRÍTICA.
}

\author{
FINALISTIC CONTROL OF TAX INCENTIVES FROM THE AIM OF LAW IN \\ SCOTT SHAPIRO'S THEORY: \\ A CRITICAL ANALYSIS.
}

\section{CONTROL FINALISTA DE INCENTIVOS TRIBUTARIOS A LA LUZ DEL PROPÓ- SITO DE LO DERECHO EN LA TEORÍA DE SCOTT SHAPIRO: UN ANÁLISIS CRÍTICO.}

\author{
https://orcid.org/0000-0001-6369-7747 / http://lattes.cnpq.br/7321457851373125 / bnogueira.rodrigo@gmail.com \\ RODRIGO NOGUEIRA \\ Procuradoria Geral do Estado do Pará, PGE/PA. \\ Belém, PA, Brasil.
}

Maria Stela Campos da Silva https://orcid.org/0000-0002-7820-9547 / http://lattes.cnpq.br/6127087703635751 / stelacampos@gmail.com Universidade Federal do Pará - UFPA. Belém, PA, Brasil.

\begin{abstract}
RESUMO
O presente artigo objetiva contribuir para o aprimoramento do controle de incentivos tributários no direito brasileiro. Neste âmbito, em que os tributos são manuseados para além da arrecadação de receitas, observa-se, em relação ao controle finalístico, baixa densidade normativa em dispositivos constitucionais e legais. Pretende-se analisar criticamente este tema a partir da tese central da teoria do direito de Scott Shapiro, qual seja, a tese do propósito moral do direito (moral aim thesis). Para tanto, o trabalho está dividido em três partes: a) na primeira, apresenta-se a tese do propósito moral do direito; b) na segunda, sustenta-se a importância de um controle de incentivos tributários com uma perspectiva finalística a partir de seu enquadramento na categoria políticas públicas; c) na terceira, analisa-se se o atual desenho normativo desta modalidade de controle contribui para o fim que caracteriza um sistema jurídico. Conclui-se que o baixo incentivo à participação de agentes externos faz com que o vigente sistema de controle finalístico destoe do propósito fundamental do direito.
\end{abstract}

Palavras-chave: Controle; Extrafiscalidade; Shapiro; Tese do propósito moral; Tributação.

\section{ABSTRACT}

This paper aims to contribute to the improvement of the control of tax incentives in Brazilian law. In this field, in which taxes are handled beyond revenue collection, it is noticed low normative density in constitutional and legal provisions on finalistic control. It is intended to critically analyze this topic from the central thesis of Scott Shapiro's theory of law, namely, the moral aim thesis. To this end, the paper is divided in three sections: a) in the first, the moral aim thesis is presented; b) in the second, the importance of a tax incentive control with a finalistic perspective is sustained from its classification as public policy; c) in the third, it is analyzed if the current normative design of this control 
contributes to the purpose that characterize a legal system. It is concluded that the low incentive to the participation of external agents makes the current system on finalistic control deviates from the fundamental purpose of the law.

Keywords: Accountability; Extra Fiscality; Shapiro; Moral aim thesis; Taxation.

\section{RESUMEN}

Este artículo tiene como objetivo contribuir a la mejora del control de los incentivos fiscales en lo derecho brasileño. En este alcance, en que se manejan los impuestos además de la recaudación de ingresos, se observa una baja densidad normativa en las disposiciones constitucionales y legales en relación con el control finalista. Se pretende analizar críticamente este tema desde la tesis central de la teoría del derecho de Scott Shapiro, a saber, la tesis del propósito moral del derecho (moral aim thesis). Para esto, el trabajo se divide en tres partes: a) en la primera, se presenta la tesis del propósito moral del derecho; b) en el segundo, la importancia de un control de incentivos fiscales con una perspectiva finalista se sustenta desde su clasificación en la categoría politica publica; c) en el tercero, analizamos si el diseño normativo actual de este tipo de control contribuye al fin que caracteriza a un sistema legal. Se concluye que el bajo incentivo a la participación de agentes externos hace que el sistema actual de control finalista se desvíe del propósito fundamental del derecho.

Palabras clave: Control; Extrafiscalidad; Shapiro; Tesis del propósito moral; Fiscalidad.

\section{SUMÁRIO}

INTRODUÇÃO; 1 O DIREITO COMO RESPOSTA PARA DISPUTAS MORAIS QUE DEMANDAM SOLUÇÃO COMPLEXA, CONTENCIOSA OU ARBITRÁRIA: A TESE CENTRAL DA TEORIA DO DIREITO DE SCOTT SHAPIRO; 2 INCENTIVOS TRIBUTÁRIOS ENQUANTO POLÍTICAS PÚBLICAS QUE DEMANDAM CONTROLE FINALÍSTICO; 3 PARTICIPAÇÃO DE AGENTES EXTERNOS: REQUISITO PARA O CONTROLE FINALÍSTICO DE INCENTIVOS TRIBUTÁRIOS; CONCLUSÃO; REFERÊNCIAS.

\section{INTRODUÇÃO}

A tributação extrafiscal, que consubstancia o manuseio do sistema tributário com vistas a incentivar comportamentos capazes de contribuir para a realização de fins constitucionais, carece de um controle efetivo das consequências que paulatinamente são produzidas na realidade social.

Com efeito, o direito brasileiro não dispõe de instrumentos normativos suficientes para o cumprimento deste desiderato, como observa Celso de Barros Correia Neto:

[...] a necessidade de fazer cumprir e aperfeiçoar os parâmetros e instrumentos jurídicos de controle hoje existentes cresce na mesma proporção do número de benefícios instituídos e do volume de receitas renunciadas. Fica claro que conter e fiscalizar a concessão de incentivos fiscais faz parte da missão de proteger o patrimônio e o interesse público. E, quanto mais frequente o uso dessas medidas, maior a importância que adquire essa tarefa.1

1 CORREIA NETO, C. de B. 0 Avesso do Tributo. 2. ed. São Paulo: Almedina, 2016. Kindle Edition. pos. 6.006 . 
A situação torna-se mais preocupante quando se direciona a atenção para a tributação extrafiscal desonerativa, caso em que os objetivos são implementados por meio de renúncia de receitas, na medida em que o impacto no orçamento público aumenta a necessidade de cuidado com a produção de efeitos compatíveis com a Constituição Federal.

No presente trabalho, pretende-se contribuir para o estudo deste tema com o seu exame a partir da tese central da teoria do direito proposta por Scott Shapiro, a tese do propósito moral do direito (moral aim thesis). De maneira mais específica, questiona-se: o atual desenho normativo desta modalidade de controle é compatível com o propósito fundamental do direito?

Para desenvolver uma resposta, o artigo está dividido em três partes: a) na primeira, apresenta-se a tese do propósito moral do direito de Shapiro; b) na segunda, sustenta-se a importância de um controle de incentivos tributários com uma perspectiva finalística a partir de seu enquadramento na categoria políticas públicas; c) na terceira, analisa-se se a atual regulamentação da matéria contribui para o fim característico do direito apresentado pelo filósofo.

\section{DIREITO COMO RESPOSTA PARA DISPUTAS MORAIS QUE DEMANDAM SOLUÇÃO COMPLEXA, CONTENCIOSA OU ARBITRÁRIA: A TESE CENTRAL DA TEORIA DO DIREITO DE SCOTT SHAPIRO.}

Scott J. Shapiro é professor de Direito e de Filosofia na Universidade de Yale, nos Estados Unidos. Seu livro Legality2, publicado em 2011, apresenta uma teoria do direito por ele chamada de Planning Theory of Law - e que pode ser traduzida por Teoria Jurídica do Planejamento Social (TJPS) ou Positivismo Jurídico dos Planos (PJP), consoante sugestão de Bruno Torrano. 3

A obra aborda diversos aspectos problemáticos da natureza do direito (validade, normatividade, autoridade, interpretação, meta-interpretação, entre outros), sendo suas ideias interessante fonte para a releitura de assuntos que interessam à dogmática jurídica brasileira.

De maneira particular, o filósofo norte-americano, como o nome de sua teoria indica, desenvolve com profundidade a visão de que as normas jurídicas se assemelham ao que chamamos de "planos". Bruno Torrano bem sintetiza esta posição:

2 SHAPIRO, S. Legality. 1. ed. Cambridge: The Belknap Press of Harvard University Press, 2013.

3 TORRANO, B. Direito como planejamento compartilhado: a teoria de Scott Shapiro. In: TORRANO, B; OMMATI, J. E. M. (coord.). O positivismo jurídico no século XXI. Rio de Janeiro: Lumen Juris, 2018. 
O comportamento das normas jurídicas e dos sistemas jurídicos são exatamente iguais ao comportamento de planos e sistemas planejadores. Planos pressupõem positividade; normas jurídicas também. Sistemas jurídicos são desenvolvidos no decorrer do tempo; sistemas planejadores também. Leis e costumes representam características de diferentes categorias de planos: a primeira, planejamento cimabaixo; os segundos, planejamento baixo-cima. Sistemas jurídicos objetivam reduzir custos de deliberação em cenários de informação assimétrica ou de dúvidas; sistemas planejadores também. E assim por diante. 4

Nesta oportunidade, será apresentada a tese que o próprio Shapiro considera central na Planning Theory of Law5: a tese do propósito moral do direito (moral aim thesis).

De acordo com Shapiro, a partir de um razoável tamanho, as sociedades passam a enfrentar problemas morais que demandam solução complexa, contenciosa ou arbitrária, como disputas envolvendo propriedade, obrigações contratuais, dever de cuidado entre seus membros, níveis de tributação, limitações do poder público, legitimidade da coerção estatal, entre outras.6

Estas controvérsias, quando se tornam sérias e numerosas, representam "circunstâncias de legalidade”. E isso porque, a partir deste momento, instrumentos ordinários de organização da ação coletiva (acordos privados, consensos, formas personalizadas de hierarquia, improvisação, ordenação espontânea, entre outras) se tornam ineficientes e inadequados para solucioná-las. A solução depende, necessariamente, de técnicas de planejamento social sofisticadas, que somente as instituições jurídicas podem disponibilizar.7

As instituições jurídicas consubstanciam uma tecnologia sofisticada de planejamento social porque viabilizam o desenvolvimento de uma densa rede de planos e planejadores sem grande custo: sua natureza hierárquica, impessoal e compartilhada permite que o sistema se torne ágil, durável e eficiente para a solução dos problemas sociais. 8

É dizer, quando as comunidades se deparam com as circunstâncias de legalidade, têm razões determinantes para reduzir os custos e riscos associados à solução de suas disputas, e assim para coordenar a ação coletiva por meio de instituições jurídicas. 9

4 TORRANO, B. Op. cit., p. 305.

5 SHAPIRO, S. Op. cit., p. 172

6 SHAPIRO, S. Op. cit., p. 173

7 SHAPIRO, S. Op. cit., p. 170

8 SHAPIRO, S. Op. cit., p. 171-172.

9 SHAPIRO, S. Op. cit., p. 173-174. 
Sistemas legais são, assim, instituições de planejamento social cujo propósito fundamental é corrigir as deficiências de métodos de planejamento alternativos em circunstâncias de legalidade.10 Espera-se das instituições legais que superem a complexidade, contenciosidade e a arbitrariedade da vida social por meio da resolução daqueles problemas que não podem ser solucionados, ou tão bem solucionados, apenas com meios não legais. 0 design institucional, neste sentido, deve garantir que os processos legais não comentam erros ou adotem métodos que façam desaparecer os benefícios morais provenientes da transição para o direito.11

Este é o propósito característico do direito, que o separa de outros sistemas normativos: atender à demanda da sociedade por um método de planejamento social capaz de remediar, de modo eficiente, os sérios e numerosos problemas morais associados às circunstâncias de legalidade.

É isto que o autor denomina tese do propósito moral (moral aim thesis).12

Shapiro esclarece que o problema fundamental solucionado pela transição para o direito não diz respeito a uma controvérsia moral particular, mas a uma questão de ordem superior, qual seja, a de como solucionar controvérsias morais em geral. As leis são "meios universais": não existem valores ou objetivos substantivos que devam realizar ou alcançar, elas apenas viabilizam que agentes com intentos complexos, valores conflitantes e habilidades limitadas alcancem fins que não seriam capazes de outro modo.13 0 direito nem sempre é bem sucedido em sua missão, e por isso pode acabar por perseguir objetivos imorais ou simplesmente por substituir equívocos morais privados por públicos14, mas "o que faz do direito o direito é que ele tem um propósito moral, não que ele satisfaz este propósito".15

A tese do propósito moral, segundo a obra, encontra suporte em pelo menos quatro razões.

Em primeiro lugar, ela explica o motivo pelo qual se considera o direito valioso. Para Shapiro, a compreensão da indispensabilidade do direito no mundo moderno, reconhecida por diversas teorias políticas, é compatível com a consideração de benefícios e custos dos vários métodos de planejamento social. Do mesmo modo, a desnecessidade de instituições jurídicas é sus-

\footnotetext{
10 SHAPIRO, S. Op. cit., p. 172.

11 SHAPIRO, S. Op. cit., p. 171.

12 SHAPIRO, S. Op. cit., p. 213-214.

13 SHAPIRO, S. Op. cit., p. 173.

14 SHAPIRO, S. Op. cit., p. 213.

15 SHAPIRO, S. Op. cit., p. 214.
} 
cetível à constatação de que suas vantagens são pequenas ou inexistentes, o que ocorre na ausência de circunstâncias de legalidade (cita-se como exemplo pequenos grupos de caçadores-coletores). 16

Em segundo lugar, a tese tem amparo na observação de que sistemas legais podem ser criticados não apenas por serem perversos, mas também por serem mal arquitetados (poorly designed), isto é, por serem incapazes de solucionar problemas morais sérios.17

Em terceiro lugar, o fato de nem todas as organizações planejadoras compulsórias serem sistemas legais confirma que a finalidade é fundamental para a definição da identidade do direito. Shapiro se vale das máfias como exemplo: os sistemas normativos destas organizações criminosas são similares ao do direito, mas as pessoas não as consideram jurídicas porque elas não se destinam ao fim dos sistemas jurídicos. 18

Por último, o fato de reagirmos à produção de benefícios morais por um sistema legal justo como se atendesse ao ponto de sua existência, não como a um acidente ou efeito colateral, também apoia a tese. A situação é diferente com as máfias, em que eventuais benefícios morais são tratados como "feliz acidente".19

O autor destaca, por fim, que este propósito moral independe da intenção dos participantes, mas deve necessariamente ser representado na prática pelos oficiais de alto escalão, ainda que sem sinceridade, para que o sistema normativo seja identificado como jurídico. É dizer, "um reino é um reino porque o rei e a sua corte o representam como tendo uma missão moral".20

Este é, em linhas gerais, o propósito do direito apresentado na Planning Theory of Law, que servirá de referência para a análise a ser empreendida adiante.

\section{INCENTIVOS TRIBUTÁRIOS ENQUANTO POLÍTICAS PÚBLICAS QUE DE- MANDAM CONTROLE FINALÍSTICO.}

Não é fácil delimitar o significado de "política pública” para fins jurídicos. Maria Paula Bucci, em obra de referência sobre o assunto, aponta mesmo a dificuldade de se identificar a forma jurídica em que o conceito se manifesta:

\footnotetext{
16 SHAPIRO, S. Op. cit., p. 172.

17 SHAPIRO, S. Op. cit., p. 173 e 214.

18 SHAPIRO, S. Op. cit., p. 215.

19 SHAPIRO, S. Op. cit., p. 216.

${ }^{20}$ SHAPIRO, S. Op. cit., p. 216-217.
} 
[. . . ] qual a expressão jurídica das políticas públicas? Política é norma? É plano? É atividade? Poder-se-ia falar em 'regime jurídico das políticas públicas'? [. . . ] Vê-se, portanto, neste ponto, que a exteriorização da política pública está muito distante de um padrão jurídico uniforme e claramente apreensível pelo sistema jurídico. Isto se reflete em dúvidas quanto à vinculatividade dos instrumentos de expressão das políticas - o seu caráter cogente em face de governos e condições políticas que mudam - e quanto à justiciabilidade dessas mesmas políticas, isto é, a possibilidade de exigir o seu cumprimento em juízo. 21

Entretanto, uma compreensão parece particularmente interessante: o conceito salienta a necessidade de que determinadas ações públicas sejam analisadas a partir de uma perspectiva finalística, objetivo que se perde - ou ao menos fica em segundo plano - no exame habitual de leis e atos administrativos.

É o que parece sugerir Fábio Konder Comparato:

A política como conjunto de normas e atos, é unificada pela sua finalidade. Os atos, decisões ou normas que a compõem, tomados isoladamente, são de natureza heterogênea e submetem-se a um regime jurídico que lhes é próprio.

De onde se segue que o juízo de validade de uma política - seja ela empresarial ou governamental - não se confunde nunca com o juízo de validade das normas e dos atos que a compõem.22

Esta ideia se justifica do ponto de vista histórico, na medida em que a importância do conceito de políticas públicas aumentou proporcionalmente ao incremento da influência do Estado sobre a realidade social - e consequentemente da necessidade de atenção aos fins desta atuação -, em especial a partir do desenvolvimento de um “constitucionalismo dirigente", consoante ensina Bucci:

De fato, há uma correspondência entre a formulação da constituição dirigente, especialmente a partir da obra de José Joaquim Gomes Canotilho, e a ideia de um direito administrativo voltado à concretização, pela Administração Pública, dos ditames constitucionais e, em decorrência, de políticas públicas. [. . . ] Assim como Canotilho trata da cooperação do legislador infraconstitucional na 'determinação' e 'conformação material' da Constituição, o enfoque das políticas públicas destaca o papel da Administração na 'determinação e conformação' material das leis e das decisões políticas a serem executadas no nível administrativo. 23

${ }^{21}$ BUCCI, M. P. D. Direito Administrativo e Políticas Públicas. 1. ed. São Paulo: Saraiva, 2016. p. 256-257. 22 COMPARATO, F. K. Ensaio sobre o juízo de constitucionalidade de políticas públicas. In: MELLO, C. A. B. (org.). Estudo em Homenagem a Geraldo Ataliba. São Paulo: Malheiros, 1997. v. 2. p. 353-354.

${ }^{23} \mathrm{BUCCl}$, M. P. D. Op. cit., p. 248-249. 
De fato, quanto mais interventoras são as funções do Estado, mais se demanda uma atenção finalística às suas atividades e mais se necessita de conceitos que contribuam para este propósito.

Definições oferecidas pela doutrina, igualmente, dão ênfase aos fins para conceituar políticas públicas.

Veja-se o conceito de Bucci: “Políticas públicas são programas de ação governamental visando a coordenar os meios à disposição do Estado e as atividades privadas, para a realização de objetivos socialmente relevantes e politicamente determinados".24

Eros Roberto Grau segue o mesmo caminho ao associar o conceito ao fim “intervenção do poder público na vida social”:

A expressão políticas públicas designa todas as atuações do Estado, cobrindo todas as formas de intervenção do poder público na vida social. E de tal forma isso se institucionaliza que o próprio direito, neste quadro, passa a manifestar-se como uma política pública - o direito é também, ele próprio, uma política pública. 25

Deste modo, classificar ações estatais como políticas públicas significa, fundamentalmente, reconhecer a importância da análise de seus fins, relegando a segundo plano discussões formais ou obrigacionais.

Neste contexto, a tributação extrafiscal pode ser caracterizada como uma das políticas públicas desenvolvidas pelo Estado. 0 próprio termo "extrafiscal”, que revela o manuseio do sistema tributário com ênfase em finalidades diversas da usual arrecadação de receitas, posiciona os fins no centro desta atividade.

De maneira particular, na esteira da classificação formulada por Eros Grau, a tributação extrafiscal consubstancia uma política pública de "intervenção sobre o domínio econômico por indução".26 Ela ainda pode ser classificada, de modo mais específico, a partir da natureza das finalidades que pretende alcançar, como destaca Ricardo Ribeiro Leite com base nos ensinamentos de Richard Musgrave: a) alocativa, quando direciona recursos para determinadas atividades em

${ }^{24}$ BUCCI, M. P. D. Op. cit., p. 241.

${ }^{25} \mathrm{GRAU}$, E. R. 0 direito posto e o direito pressuposto. 7. ed. São Paulo: Malheiros, 2008. p. 26.

${ }^{26}$ São três as modalidades as modalidades em que Eros Grau divide a intervenção do Estado em questões econômicas: a) intervenção por absorção ou participação (intervenção no domínio econômico): o Estado desenvolve a ação enquanto agente econômico, em regime de monopólio (absorção) ou competição (participação); b) intervenção por direção (primeira hipótese de intervenção sobre o domínio econômico): o Estado cria mecanismos e normas de comportamento compulsório para os agentes econômicos; c) intervenção por indução (segunda hipótese de intervenção sobre o domínio econômico): o Estado manipula os instrumentos de intervenção em consonância e na conformidade das leis que regem o mercado (GRAU, E. R. A ordem econômica na Constituição de 1988. 14. ed. São Paulo: Malheiros, 2012. p. 143). 
detrimento de outras; b) distributiva, quando se destina à redistribuição da renda; c) estabilizadora, quando pretende garantir níveis de emprego, preços e estabilidade macroeconômica. 27

Este último ponto de vista evidencia, de maneira nítida, a importância de um controle finalístico, como se deduz da seguinte observação do mesmo autor:

Nesse sentido, sobre a tributação extrafiscal incidem as limitações e regramentos decorrentes tanto de seu instrumento, o regime jurídico tributário, quanto de sua finalidade, a intervenção indutora sobre o espaço econômico com intuito alocativo, distributivo ou estabilizador. A capacidade de intervenção extrafiscal dos tributos, se tomada como discricionária da pessoa política competente para instituir os tributos, ignora que a constituição estabeleceu limites, finalidades, objetivos e formas para qualquer intervenção econômica do Estado brasileiro e expressamente sobre a intervenção econômica por meio de alguns impostos. 28

$\mathrm{Na}$ vertente desonerativa, a tributação extrafiscal se torna ainda mais delicada, porquanto implica um "efeito externo de renúncia" ao lado de um "efeito externo de incentivo", como leciona Celso de Barros Correia Neto:

[. . . ] parece correto afirmar que incentivo fiscal e renúncia de receita também poderiam ser concebidos como efeitos externos. Não seriam, todavia, consequências da regra do tributo, mas da regra de exoneração. No primeiro, tem-se o que chamamos, neste estudo, de "efeito externo de incentivo", que é a realização concreta das condutas incentivadas pela supressão ou redução dos encargos fiscais, mediante concessão do benefício fiscal. No segundo, tem-se o "efeito externo de renúncia", isto é, as repercussões financeiras da aplicação da exoneração concedida, no tocante à perda de arrecadação tributária. Em outras palavras, é o quanto se deixa de arrecadar por conta da aplicação do incentivo fiscal.29

Trata-se, em outras palavras, de um gasto tributário, conceito cuja origem histórica é bem explicada por Patrícia Sayd:

A renúncia fiscal também é denominada de gasto tributário. Na realidade, o termo gasto tributário foi empregado pela primeira vez em 1967 pelo prof. Stanley Surrey, Secretário - Assistente do Tesouro dos Estados Unidos para Política Tributária de 1961 a 1969 (Surrey, 1973). A expressão tem sido utilizada para descrever os dispositivos especiais do imposto de renda federal que representam renúncia de receitas (portanto perdas governamentais), feitos por meio desse imposto para

${ }^{27}$ RIBEIRO, R. L. Direito Econômico da Tributação: uma análise da extrafiscalidade no sistema tributário brasileiro. 2013. 150 p. Dissertação (Mestrado em Direito) - Faculdade de Direito da Universidade de São Paulo. p. 71-77.

${ }^{28}$ RIBEIRO, R. L. Op. cit., p. 84.

${ }^{29}$ CORREIA NETO, C. de B. Op. cit., pos. 3838-3847. 
alcançar diversos objetivos econômicos e sociais, abrangendo um grupo relativamente restrito de contribuintes, setor ou região, e que, em princípio, poderia ser substituído por um programa de gasto direto (Rosa, 1996).

Surrey (1973) considera que os dispositivos de reduções, deduções e isenções contidos no imposto de renda constituem, na verdade, uma forma de se prover assistência financeira governamental. O Governo, ao invés de arrecadar e gastar diretamente em cada setor, região ou grupo de contribuintes que por interesse econômico e político venham a ser eleitos áreas de investimento tributário, opta por deixar de arrecadar, gerando perda de receita, que pode ser entendida como despesa. Como em seus propósitos, a renúncia fiscal se assemelha aos gastos orçamentários do Governo, mas estes são realizados por intermédio da redução de arrecadação tributária e não por desembolso di-reto. Os gastos tributários são considerados gastos realizados por meio do sistema tributário, portanto se caracterizam como gastos indiretos (Surrey, 1973). 30

A atenção aos fins, portanto, é mais rigorosa pelo dispêndio de recursos públicos - podese mesmo dizer que neste caso a política não passa de um atalho para um pagamento direto pelo governo, dispensando o trabalho de arrecadar o tributo e em seguida transferi-lo ao particular.31

Fica claro, assim, que incentivos tributários se enquadram na categoria políticas públicas e, consequentemente, como ínsito ao conceito, demandam especial controle sob uma perspectiva finalística.

Mas pode-se dizer que o atual desenho normativo desta modalidade de controle, em relação aos incentivos tributários, é compatível com o propósito fundamental do direito?

\section{PARTICIPAÇÃO DE AGENTES EXTERNOS: REQUISITO PARA O CONTROLE FINALÍSTICO DE INCENTIVOS TRIBUTÁRIOS.}

Determinar os níveis de tributação em uma comunidade certamente é um problema moral que demanda solução social complexa, contenciosa ou arbitrária - basta conferir os desacordos entre filósofos, economistas e cientistas sociais sobre o assunto.

A tributação extrafiscal desonerativa não apenas não escapa deste contexto, como o seu potencial impacto sobre a isonomia torna os problemas morais ainda mais sérios. É o que observa Richard Musgrave:

Devemos apenas observar que a utilização regulatória da tributação acarreta um custo social, sob a forma de diminuição da equidade na estrutura tributária; e

\footnotetext{
${ }^{30}$ SAYD, P. D. Renúncia Fiscal e Equidade na Distribuição de Recursos para a Saúde. Instituição: Agência Nacional de Saúde Suplementar/Ministério da Saúde.

31 BURTON, M.; SADIQ, K. Tax Expenditure Management: A critical assessment. Cambridge: Cambridge University Press, 2013. p. 2.
} 
devemos levar em conta este custo quando escolhermos entre impostos e outros tipos de controle. 32

Deste modo, no vocabulário de Shapiro, estas disputas se incluem entre as circunstâncias de legalidade. Assim sendo, as normas legais que a ela se direcionam podem ser examinadas a partir do objetivo central e primário proposto pela tese do propósito moral. Não se trata, conforme dito, de verificar a conformidade do direito com reivindicações morais particulares, mas de analisar se as regras viabilizam boas soluções para tais circunstâncias.

Em relação aos incentivos tributários, o sistema jurídico prevê, em um primeiro momento, a solução de disputas por meio de regras sobre o modo como as políticas devem ser criadas (sistema de governo, divisão de competências, eleição de representantes parlamentares, processo legislativo, entre outras) - momento que não é objeto do presente trabalho.

Em um segundo momento, posterior à criação, apresenta-se o sistema de controle, que objetiva assegurar que soluções anteriores - especialmente as de maior hierarquia, pactuadas na Constituição Federal - restam respeitadas pela solução mais recente.

O controle finalístico destas políticas, assim, se justifica não pela necessidade de reavaliar os problemas morais complexos, contenciosos ou arbitrários implícitos, resolvidos no momento da criação, mas tão somente para garantir que as decisões se harmonizam com propósitos do Estado brasileiro, estabelecidos na Lei Fundamental.

O que se propõe na presente oportunidade é que, sem uma propriedade elementar, o controle finalístico dos incentivos tributários não pode ser realizado sem apenas retomar as circunstâncias de legalidade próprias da criação da política: a participação de agentes externos no processo de controle.

Esta conclusão é consequência de uma observação factual: as informações relativas aos efeitos destas políticas não estão disponíveis, qualitativa e/ou quantitativamente, a todos os agentes sociais, o que inclui os oficiais do sistema com função controladora.

Com efeito, os resultados produzidos por estas políticas se dissipam por variáveis múltiplas e complexas, o que dificulta a sua compreensão; além disso, a análise pode ser empreendida a partir de metodologias diversas, o que implica em inevitável seletividade.

José Maria Arruda de Andrade bem introduz o seu leitor a estas dificuldades, discriminando a variedade de modelos disponíveis para avaliação:

32 MUSGRAVE, R. Teoria das Finanças Públicas: Um estudo de economia governamental. São Paulo: Atlas, 1973. v. 1. Trad: Auriphebo Berrance Simões. p. 228. 
Várias são as formas de se avaliar, e com certeza, as fragilidades dos modelos e as dificuldades não devem servir de escusa à necessidade de avaliação crítica das políticas implementadas.

Muitas vezes, a análise se dá em termos estáticos. [...] Ou seja, busca-se mensurar qual seria a tributação normal caso não houvesse a renúncia estudada e, depois, calcula-se a renúncia imaginando o recolhimento potencial (estático). 0 pressuposto é de que a renúncia não tem efeito futuro e dinâmico sobre o mercado [...]. Além de análises estáticas, há técnicas dinâmicas retrospectivas e prospectivas. Os métodos retrospectivos buscam analisar os dados disponíveis (pretéritos) para avaliar a medida. Quando se analisa esses dados, busca-se isolar as variáveis de interesse, visando segregar as alterações causadas pela medida daquelas alterações causadas por outros fatores alheios à política. Justamente por se tratar de vários expedientes não simples que se pode até questionar se se está de fato diante de um método empírico. Ainda assim, a análise retrospectiva que busca compreender e segregar os efeitos causados diretamente pela medida tem a vantagem de melhor avaliar os resultados em questão. Um desses métodos é o econométrico (das diferenças nas diferenças, de controle sintético etc.).

Por fim, existem modelos que buscam simular os efeitos esperados de uma medida, a partir de teorias de equilíbrio de mercado e a partir do uso de sistemas de informática. Trata-se de método prospectivo, que tem na análise de equilíbrio geral computacional seu melhor exemplo. Também aqui pode-se questionar as premissas do modelo que busca simular o comportamento dos agentes de mercado, tendo em vista a complexidade de se prever todas as ações desses agentes. Mas, acima de tudo, não se deve esquecer que é melhor uma política econômica que busque subsídios, ainda que limitados, em métodos estudados por diversos pesquisadores do que a mera intuição do agente político dotado de poder para implantar uma medida econômica.33

Sem incentivo à participação de agentes externos, capazes de enriquecer a pluralidade informacional, o controle não tem aptidão para confrontar resultados de políticas e fins constitucionais com solidez, o que apenas alimenta a retomada das circunstâncias de legalidade.

Não obstante esta constatação, o incentivo à participação de agentes externos neste campo ainda é incipiente no direito brasileiro.

A bem da verdade, o sistema jurídico nacional privilegia quase que exclusivamente 0 controle formal destas políticas, o que se observa pelas modalidades identificadas por Celso de Barros Correia Neto em estudo específico sobre o tema: a) controle de forma, consistente na reserva de lei específica para a instituição (art. 150, §6 ${ }^{\circ} \mathrm{CF}$ ); b) controle de transparência, consubstanciado na necessidade de inclusão de demonstrativo regionalizado de seus impactos em projetos de lei orçamentária (art. $165, \S 6^{\circ}, \mathrm{CF}$ ); c) controle de impacto financeiro-orçamentário,

${ }^{33}$ ANDRADE, J. M. de A. Avaliação de eficiência e efetividade é necessária em nossa política econômica. Revista Consultor Jurídico, São Paulo, 2016. Disponível em: https://www.conjur.com.br/2016-fev-21/estado-economia-avaliacao-eficiencia-necessaria-nossa-politica-economica. Acesso em: ago. 2019. 
que é a necessidade de estudo do equilíbrio de contas públicas antes da implementação (art. 14 da Lei Complementar no 101/2000).34

0 controle finalístico pode ser encontrado no art. 70 da Constituição Federal, na medida em que o dispositivo menciona "renúncias de receitas" como uma dos objetos de controle a ser exercido pelo controle externo, a cargo do Congresso Nacional, com auxílio do Tribunal de Contas (art. 71), e pelos órgãos de controle interno de cada Poder (art. 74). 35

Entretanto, não existe densidade normativa na norma constitucional, como se procede em relação ao controle formal. A abertura à participação de agentes externos ao órgão controlador, deste modo, é feita apenas por normas constitucionais gerais, como o direito de petição (art. $5^{\circ}$, XXXIV, “a”, CF), a possibilidade de prestar informações ao Congresso Nacional (art. 58, §2 CF) e a oportunidade de denunciar irregularidades e ilegalidades aos Tribunais de Contas (art. 74, $\S 2^{\circ}, \mathrm{CF}$ ), o que relega a intensidade dessa participação à decisão das próprias instituições controladoras. 36

Esta qualidade fundamental somente foi reconhecida por iniciativas normativas pontuais no direito brasileiro.

Este foi o caso da Lei Federal $n^{\circ} 12.546 / 2011$, que instituiu a política de desoneração da folha de pagamento suportados por setores econômicos nela discriminados. Por meio do diploma legal, a União criou uma comissão tripartite formada por representantes de trabalhadores, empresários e Poder Executivo federal para acompanhamento e avaliação da implementação da política (art. 10).37 Além disso, o Decreto Federal $n^{\circ} 7.711 / 2012$, que regulamentou a comissão (“Comissão Tripartite de Acompanhamento e Avaliação da Desoneração da Folha de Pagamentos CTDF”), incentivou expressamente a participação de terceiros, como evidencia o art. 2, §1”: “Para

\footnotetext{
${ }^{34}$ CORREIA NETO, C. de B. Op. cit.

${ }^{35}$ BRASIL. Constituição Federal. Brasília: Senado Federal, 1988. Disponível em: http://www.planalto.gov.br/ccivil_03/constituicao/ConstituicaoCompilado.htm . Acesso em: ago. 2019.

${ }^{36}$ BRASIL. Constituição Federal. Brasília: Senado Federal, 1988. Disponível em: http://www.planalto.gov.br/ccivil_03/constituicao/ConstituicaoCompilado.htm . Acesso em: ago. 2019.

${ }^{37}$ BRASIL. Lei $n^{\circ} 12.546$ de 14 de dezembro de 2011. Institui o Regime Especial de Reintegração de Valores Tributários para as Empresas Exportadoras (Reintegra); dispõe sobre a redução do Imposto sobre Produtos Industrializados (IPI) à indústria automotiva; altera a incidência das contribuições previdenciárias devidas pelas empresas que menciona; altera as Leis $\mathrm{n}^{\circ} 11.774$, de 17 de setembro de $2008, \mathrm{n}^{\circ} 11.033$, de 21 de dezembro de 2004, $n^{\circ} 11.196$, de 21 de novembro de $2005, n^{\circ} 10.865$, de 30 de abril de 2004, $n^{\circ} 11.508$, de 20 de julho de 2007, $n^{\circ} 7.291$, de 19 de dezembro de 1984, $n^{\circ} 11.491$, de 20 de junho de 2007, $n^{\circ} 9.782$, de 26 de janeiro de 1999, e ${ }^{\circ} 9.294$, de 15 de julho de 1996, e a Medida Provisória ${ }^{\circ}$ 2.199-14, de 24 de agosto de 2001; revoga o art. $1^{\circ}$ da Lei $n^{\circ} 11.529$, de 22 de outubro de 2007, e o art. $6^{\circ}$ do Decreto-Lei $n^{\circ} 1.593$, de 21 de dezembro de 1977, nos termos que especifica; e dá outras providências. In: Diário Oficial da República Federativa do Brasil, Brasília, DF, 15 dez. 2011. Disponível em: http://www.planalto.gov.br/ccivil_03/_ato2011-2014/2011/lei/l12546.htm . Acesso em: ago. 2019.
} 
O CONTROLE FINALÍSTICO DE INCENTIVOS TRIBUTÁRIOS À LUZ DO PROPÓSITO DO DIREITO NA TEORIA DE SCOTT SHAPIRO: UMA ANÁLISE CRÍTICA.

a execução das atribuições referidas no caput, a CTDF poderá convidar especialistas, pesquisadores e representantes de outros órgãos e entidades públicas ou privadas". 38

Em outros domínios jurídicos, sujeitos a características similares, é usual o incentivo à participação de agentes externos para fins de controle.

As audiências públicas na área ambiental (Resolução nº 9/1987 do Conselho Nacional do Meio Ambiente - CONAMA)39, as comissões plurais de gestão de políticas de seguridade social (art. 194, parágrafo único, VII, Constituição Federal)40, a realização de audiências públicas pelo Supremo Tribunal Federal (art. $9^{\circ}, \$ 1^{\circ}$ e $20, \$ 1^{\circ}$, Lei $n^{\circ} 9.868 / 99$ e $6^{\circ}, \S 1^{\circ}$, da Lei $n^{\circ} 9.882 / 99$ ) 4142 e a admissão de amicus curiae (art. 138 do Código de Processo Civil de 2015, Lei n 13.105/05)43 são notáveis exemplos.

Vale observar, para confirmar a disseminação desta abertura em determinadas áreas, que Diogo de Figueiredo Moreira Neto chegou a classificar a intensidade da participação da sociedade civil em políticas públicas em quatro níveis: participação informativa, participação na execução, participação pela consulta e participação na decisão. 44

Com escasso incentivo à pluralidade, o controle finalístico de incentivos tributários tende a apenas reconduzir o debate às circunstâncias de legalidade superadas por ocasião de sua criação.

${ }^{38}$ BRASIL. Decreto $n^{\circ} 7.711$ de 3 de abril de 2012. Regulamenta o disposto no art. 10 da Lei $n^{\circ} 12.546$, de 14 de dezembro de 2011, e institui Comissão Tripartite de Acompanhamento e Avaliação da Desoneração da Folha de Pagamentos. In: Diário Oficial da República Federativa do Brasil, Brasília, DF, 04 abr. 2012. Disponível em: http://www.planalto.gov.br/ccivil_03/_ato2011-2014/2012/decreto/D7711.htm . Acesso em: ago. 2019.

39 BRASIL. Ministério do Meio Ambiente. Conselho Nacional do Meio Ambiente. RESOLUÇÃO CONAMA no 9 de 3 de dezembro de 1987. In: Diário Oficial da República Federativa do Brasil, Brasília, DF, 5 jul. 1990. Disponível em: http://www2.mma.gov.br/port/conama/legiabre.cfm?codlegi=60 . Acesso em: ago. 2019. ${ }^{40}$ BRASIL. Constituição Federal. Brasília: Senado Federal, 1988. Disponível em: http://www.planalto.gov.br/ccivil_03/constituicao/ConstituicaoCompilado.htm . Acesso em: ago. 2019.

${ }^{41}$ BRASIL. Lei $n^{\circ} 9.868$ de 10 de novembro de 1999. Dispõe sobre o processo e julgamento da ação direta de inconstitucionalidade e da ação declaratória de constitucionalidade perante o Supremo Tribunal Federal. In: Diário Oficial da República Federativa do Brasil, Brasília, DF, 11 nov. 1999. Disponível em: http://www.planalto.gov.br/ccivil_03/LEIS/L9868.htm . Acesso em: ago. 2019.

42 BRASIL. Lei $n^{\circ} 9.882$ de 3 de dezembro de 1999. Dispõe sobre o processo e julgamento da argüição de descumprimento de preceito fundamental, nos termos do § 10 do art. 102 da Constituição Federal. In: Diário Oficial da República Federativa do Brasil, Brasília, DF, 6 dez. 1999. Disponível em: http://www.planalto.gov.br/ccivil_03/leis/19882.htm . Acesso em: ago. 2019.

${ }^{43}$ BRASIL. Lei $n^{\circ} 13.105$ de 16 de março de 2015. Código de Processo Civil. In: Diário Oficial da República Federativa do Brasil, Brasília, DF, 17 mar. 2015. Disponível em: http://www.planalto.gov.br/ccivil_03/_ato2015-2018/2015/lei/l13105.htm . Acesso em: ago. 2019.

${ }^{44}$ MOREIRA NETO, D. de F. Direito da participação política: legislativa, administrativa, judicial, fundamentos e técnicas constitucionais da legitimidade. Rio de Janeiro: Renovar, 1992. p. 88-90. 


\section{CONCLUSÃO}

Segundo a teoria de Scott Shapiro, o direito é um método de planejamento social que tem um propósito moral: remediar, de modo eficiente, os dificuldades associadas às circunstâncias de legalidade (o acúmulo e seriedade de problemas morais que demandam solução complexa, contenciosa ou arbitrária).

Este ponto de vista é interessante porque permite analisar criticamente sistemas jurídicos a partir de um objetivo central que independe de considerações morais particulares.

Considerando que as políticas públicas de tributação extrafiscal desonerativa buscam solucionar circunstâncias de legalidade, é possível analisá-las sob esta ótica.

Neste contexto, identifica-se dois momentos para a solução das disputas que envolvem estas políticas: a) no primeiro, com o estabelecimento de regras sobre o modo como elas devem ser criadas (sistema de governo, divisão de competências, regras para eleição de representantes parlamentares, processo legislativo, entre outras); b) no segundo, posteriormente à criação, a partir de um sistema de controle, que busca assegurar a solução mais recente respeita as anteriores, em especial as pactuadas na Constituição Federal.

0 controle finalístico, nesta linha de raciocínio, destina-se a verificar a harmonia destas políticas com as soluções a respeito dos fins a serem buscados pelo Estado, previstos na Constituição Federal.

Ocorre que a inexistência de incentivo à participação de agentes externos ao controlador, verificada no sistema jurídico brasileiro, faz com que este controle careça de subsídios para o cumprimento de sua função. Com efeito, levando em consideração que os resultados produzidos por estas políticas se dissipam por variáveis múltiplas e complexas, e que a sua avaliação pode ser empreendida a partir de metodologias diversas, percebe-se que, sem esta abertura, não é possível confrontar resultados e fins constitucionais.

Sem mecanismos para assegurar pluralidade, o controle finalístico tende a apenas retomar circunstâncias de legalidade superadas por ocasião da criação das políticas, e assim destoa do propósito fundamental do direito. 


\section{REFERÊNCIAS}

ANDRADE, J. M. de A. Avaliação de eficiência e efetividade é necessária em nossa política econômica. Revista Consultor Jurídico, São Paulo, 2016. Disponível em: https://www.conjur.com.br/2016-fev-21/estado-economia-avaliacao-eficiencia-necessaria-nossa-politica-economica . Acesso em: ago. 2019.

BRASIL. Constituição Federal. Brasília: Senado Federal, 1988. Disponível em: http://www.planalto.gov.br/ccivil_03/constituicao/ConstituicaoCompilado.htm . Acesso em: ago. 2019.

BRASIL. Decreto $n^{\circ} 7.711$ de 3 de abril de 2012. Regulamenta o disposto no art.10 da Lei $n^{\circ}$ 12.546, de 14 de dezembro de 2011, e institui Comissão Tripartite de Acompanhamento e Avaliação da Desoneração da Folha de Pagamentos. In: Diário Oficial da República Federativa do Brasil, Brasília, DF, 04 abr. 2012. Disponível em: http://www.planalto.gov.br/ccivil_03/_ato20112014/2012/decreto/D7711.htm . Acesso em: ago. 2019.

BRASIL. Lei $n^{\circ} 9.868$ de 10 de novembro de 1999. Dispõe sobre o processo e julgamento da ação direta de inconstitucionalidade e da ação declaratória de constitucionalidade perante o Supremo Tribunal Federal. In: Diário Oficial da República Federativa do Brasil, Brasília, DF, 11 nov. 1999. Disponível em: http://www.planalto.gov.br/ccivil_03/LEIS/L9868.htm . Acesso em: ago. 2019.

BRASIL. Lei no 9.882 de 3 de dezembro de 1999. Dispõe sobre o processo e julgamento da argüição de descumprimento de preceito fundamental, nos termos do § 10 do art. 102 da Constituição Federal. In: Diário Oficial da República Federativa do Brasil, Brasília, DF, 6 dez. 1999. Disponível em: http://www.planalto.gov.br/ccivil_03/leis/19882.htm . Acesso em: ago. 2019.

BRASIL. Lei no 12.546 de 14 de dezembro de 2011. Institui o Regime Especial de Reintegração de Valores Tributários para as Empresas Exportadoras (Reintegra); dispõe sobre a redução do Imposto sobre Produtos Industrializados (IPI) à indústria automotiva; altera a incidência das contribuições previdenciárias devidas pelas empresas que menciona; altera as Leis $n^{\circ} 11.774$, de 17 de setembro de 2008, $\mathrm{n}^{\circ} 11.033$, de 21 de dezembro de 2004, $\mathrm{n}^{\circ} 11.196$, de 21 de novembro de 2005, $\mathrm{n}^{\circ} 10.865$, de 30 de abril de 2004, $\mathrm{n}^{\circ} 11.508$, de 20 de julho de 2007, $\mathrm{n}^{\circ} 7.291$, de 19 de dezembro de 1984, $n^{\circ} 11.491$, de 20 de junho de $2007, n^{\circ} 9.782$, de 26 de janeiro de 1999 , e $n^{\circ}$ 9.294, de 15 de julho de 1996, e a Medida Provisória $n^{\circ} 2.199-14$, de 24 de agosto de 2001; revoga 0 art. $1^{\circ}$ da Lei $n^{\circ} 11.529$, de 22 de outubro de 2007, e o art. $6^{\circ}$ do Decreto-Lei $n^{\circ} 1.593$, de 21 de dezembro de 1977, nos termos que especifica; e dá outras providências. In: Diário Oficial da República Federativa do Brasil, Brasília, DF, 15 dez. 2011. Disponível em: http://www.planalto.gov.br/ccivil_03/_ato2011-2014/2011/lei/l12546.htm . Acesso em: ago. 2019.

BRASIL. Lei nº 13.105 de 16 de março de 2015. Código de Processo Civil. In: Diário Oficial da República Federativa do Brasil, Brasília, DF, 17 mar. 2015. Disponível em: http://www.planalto.gov.br/ccivil_03/_ato2015-2018/2015/lei/l13105.htm . Acesso em: ago. 2019.

BRASIL. Ministério do Meio Ambiente. Conselho Nacional do Meio Ambiente. RESOLUÇÃO CONAMA no 9 de 3 de dezembro de 1987. In: Diário Oficial da República Federativa do Brasil, Brasília, DF, 5 jul. 1990. Disponível em: http://www2.mma.gov.br/port/conama/legiabre.cfm?codlegi=60 . Acesso em: ago. 2019.

BUCCI, M. P. D. Direito Administrativo e Políticas Públicas. São Paulo: Saraiva, 2016. 
BURTON, M.; SADIQ, K. Tax Expenditure Management: A critical assessment. Cambridge: Cambridge University Press, 2013.

COMPARATO, F. K. Ensaio sobre o juízo de constitucionalidade de políticas públicas. In: MELLO, C. A. B. (org.). Estudo em Homenagem a Geraldo Ataliba. São Paulo: Malheiros, 1997. v. 2.

CORREIA NETO, C. de B. 0 Avesso do Tributo. 2. ed. São Paulo: Almedina, 2016. Kindle Edition.

GRAU, E. R. O direito posto e o direito pressuposto. 7. ed. São Paulo: Malheiros, 2008.

GRAU, E. R. A ordem econômica na Constituição de 1988. 14. ed. São Paulo: Malheiros, 2012.

MOREIRA NETO, D. de F. Direito da participação política: legislativa, administrativa, judicial, fundamentos e técnicas constitucionais da legitimidade. Rio de Janeiro: Renovar, 1992.

MUSGRAVE, R. Teoria das Finanças Públicas: Um estudo de economia governamental. São Paulo: Atlas, 1973. v. 1. Trad: Auriphebo Berrance Simões.

RIBEIRO, R. L. Direito Econômico da Tributação: uma análise da extrafiscalidade no sistema tributário brasileiro. 2013. 150 p. Dissertação (Mestrado em Direito) - Faculdade de Direito da Universidade de São Paulo.

SAYD, P. D. Renúncia Fiscal e Equidade na Distribuição de Recursos para a Saúde. Instituição: Agência Nacional de Saúde Suplementar/Ministério da Saúde.

SHAPIRO, S. Legality. 1. ed. Cambridge: The Belknap Press of Harvard University Press, 2013.

TORRANO, B. Direito como planejamento compartilhado: a teoria de Scott Shapiro. In: TORRANO, B; OMMATI, J. E. M. (coord.). O positivismo jurídico no século XXI. Rio de Janeiro: Lumen Juris, 2018.

Recebido em: 16.08.2019/ Aprovado em: 11.08.2021 / Publicado em: 13.08.2021

\section{COMO FAZER REFERÊNCIA AO ARTIGO (ABNT):}

NOGUEIRA, Rodrigo; SILVA, Maria Stela Campos da. O controle finalístico de incentivos tributários à luz do propósito do direito na teoria de Scott Shapiro: uma análise crítica. Revista Eletrônica do Curso de Direito da UFSM, Santa Maria, RS, v. 15, n. 3, e39586. 2020. ISSN 1981-3694. DOI:

http://dx.doi.org/10.5902/1981369439586. Disponível em: https://periodicos.ufsm.br/revistadireito/article/view/39586 Acesso em: dia mês. ano.

Direitos autorais 2020/2021 Revista Eletrônica do Curso de Direito da UFSM

Editores responsáveis: Rafael Santos de Oliveira e Angela Araujo da Silveira Espindola

Esta obra está licenciada com uma Licença Creative Commons Atribuição-NãoComercial-SemDerivações 4.0 Internacional.

\section{SOBRE OS AUTORES}

RODRIGO NOGUEIRA

Mestre em Direito (UFPA). Especialista em Advocacia Pública (AVM Educacional) e Direito Tributário (FGV). Procurador do Estado do Pará.

MARIA STELA CAMPOS DA SILVA

Graduada em Direito pela Universidade Federal do Pará (2000) com especialização e mestrado em Direito pela Universidade Federal de Pernambuco (2002). Doutorado em Direito pela Universidade Federal do Pará (2014). Atualmente é professora da graduação e pósgraduação em Direito (mestrado e doutorado acadêmico - PPGD - Programa de Pós-Graduação em Direito; e mestrado profissional PPGDDA - Programa de Pós-Graduação em Direito e Desenvolvimento na Amazônia) da Universidade Federal do Pará. Advogada - Alberto Campos Advogados Associados. Tem experiência na área de Direito, com ênfase em Direito Público, Financeiro e Tributário. 